\title{
Development of photodiode via the rapid melt growth (RMG) materials for energy conversion device
}

\author{
N. Zainal ${ }^{1}$, S. J.N.Mitchell ${ }^{2}$, D. W. McNeill ${ }^{3}$, W. M. Jubadi ${ }^{4}$ \\ ${ }^{1,4}$ Faculty of Electrical \& Electronic Engineering (FKEE), Universiti Tun Hussein Onn Malaysia (UTHM), Malaysia \\ ${ }^{2,3}$ School of Electronics, Electrical Engineering and Computer Science, Queens University Belfast, United Kingdom
}

\begin{tabular}{l} 
Article Info \\
\hline Article history: \\
Received Jul 26, 2019 \\
Revised Oct 27, 2019 \\
Accepted Nov 13, 2019 \\
\hline
\end{tabular}

Keywords:

Energy conversion device Ge photodiode

Ge resistor

Germanium (GE)

Photovoltaic (PV)

Rapid melt growth (RMG)

Thermophotovoltaic (TPV)

\begin{abstract}
Germanium (Ge) photodiodes were fabricated with the new RMG crucible materials that were established in this study. Results show that Ge large square patterns with size of $208 \mu \mathrm{m} \times 208 \mu \mathrm{m}$ were unable to be achieved if ion implantation process was used in formation of photodiode. Delamination can be observed on all test samples during polycrystalline silicon (poly-Si) deposition at $620 \mathrm{oC}$. This result was in contrast to a previous intrinsic $\mathrm{Ge}$ test structure, where good formation of squares with size similar to that 208 $\mu \mathrm{m} \times 208 \mu \mathrm{m}$ had been successfully attained even with high annealing temperature above 938 oC. This indicates that doping through ion implantation has affected Ge film and caused delamination even at low temperature. However, good formations of $\mathrm{Ge}$ stripes were attained along with the ion implantation process in fabricating the photodiode. Results show that the sheet resistance of Ge stripe has significantly decreased compared to previous Ge resistors. The better resistance is due to the thicker $(500 \mathrm{~nm}) \mathrm{Ge}$ layer. In the case of Ge stripes with a p-i-n junction, only small fraction of test samples have shown a diode characteristic but with high leakage current. Results of I-V measurement show that a large fraction of test samples produced resistor characteristics. The high leakage current is believed due to the fact that the Ge films formed at this stage were polycrystalline in structure. Thus the grain size of Ge stripe has affected the performance. Slight changes on the I-V characteristic of single Ge can be observed when samples were tested under illumination. Therefore, it has potential to be used for future development of energy conversion device.
\end{abstract}

Copyright (@ 2020 Institute of Advanced Engineering and Science. All rights reserved.

\section{Corresponding Author:}

Nurfarina Zainal,

Faculty of Electrical \& Electronic Engineering (FKEE),

Universiti Tun Hussein Onn Malaysia (UTHM),

Parit Raja, 86400 Batu Pahat, Johor, Malaysia.

Email: nurfarina@uthm.edu.my

\section{INTRODUCTION}

Over the past decade there has been a rapid development of energy conversion devices such as photovoltaic (PV) cells or solar cells that convert solar energy into electrical energy. Thermophotovoltaic (TPV) cell is another conversion device that has similar approach except it converts thermal energy such as radiator into electrical energy. The rapid growth of these energy conversion devices are due to the issues of depleting fossil sources, greenhouse gases and fluctuating fuel and oil prices which has forced researchers to find an alternative renewable energy. Solar is one kind of renewable energy that is free to be used. Over a period of time, extensive research on development of solid-state solar cells has been investigated to achieve high conversion efficiency, which has resulted in single and multi-junction structures. The most efficient semiconductor solar cells to be reported consist of triple junctions via concentrator system for terrestrial application with $41.6 \%$ efficiency [1]. This compares to stand alone solar cells with energy conversion 
of $7.8 \%$ for the case of bulk germanium device passivation layer [2]. In multi-junction system, one can achieve highest efficiency solar cells by combining the bandgaps of lattice matched semiconductor materials $[3,4]$ namely as III-V or II-VI cells. To date, the highest energy conversion efficiency (40\%) for terrestrial application is from a triple junction solar cell with Ge substrate. This has surpassed the efficiency of mature Si based solar cells $(28 \%)$. However, higher cost will be incurred for an overall system of triple junction solar cells in a flat panel for terrestrial application.

Efforts have also attempted to resolve the expense issue by finding materials that have good photovoltaic properties in parallel with a low cost per unit power generation. According to Wadia et al., [5] iron sulphide has been revealed as the cheapest material per unit power generation compared to 23 inorganic materials used for photovoltaic devices [5]. Most of the solar cell development using pyrite has used electrochemical cells rather than solid-state structures. A solid-state solar cell has been produced using pyrite but has low performance with only $1 \%$ conversion efficiency [6]. The best performance of pyrite electrochemical solar cells achieved only $2.8 \%$ efficiency conversion [5]. Despite pyrite or iron sulphide being the cheapest photovoltaic material, the conversion performance is low compared to existing solar cells due to the instability in stoichiometry of pyrite during the development process. Low cost materials such as metal sulphides do not offer better performance, and the reproducible process might remain complicated hence, less viable to produce. On the other hand, germanium $(\mathrm{Ge})$ has good properties with a low band gap $(\mathrm{Eg}=0.66 \mathrm{eV})$ [7] compared to metal sulphide, iron $(\mathrm{Eg}=0.95 \mathrm{eV})$ and silicon $(\mathrm{Eg}=1.1 \mathrm{eV})$. Energy can be absorbed from the infrared region of solar or thermal spectrum and then converted into electrical energy due to the low band gap. Ge also has been used in multi junction photovoltaic stack for space solar cells application and revealed high energy conversion performance [3, 8].

In case of TPV cells, they can be used for hybrid electric vehicles, recovery of waste heat from industrial process [9] and hybrid solar-powered/fuel fired system during night periods [10]. However, the application of the device has not been commerciallised. In TPV cells, materials with low band gap, within the range of 0.5 to $0.74 \mathrm{eV}$, (infrared region) were preferred [11]. The reasons are because photocells in infrared region are able to convert thermal energy from radiators with typical temperature 1200 to $1450 \mathrm{oC}$ to electrical energy with higher efficiency compared to silicon (Si) TPV cells. Despite Si being low in cost and easily available material, it is less viable to be used for TPV cells due to the higher band gap (1.12 eV) where most of the thermal radiation will fall short, thus less energy is converted [9]. The highest conversion energy TPV cells use gallium antimonide ( $\mathrm{GaSb}$ ) with $0.72 \mathrm{eV}$ band gap giving efficiency up to $20.5 \%$ along with the rear mirror [12]. However, due to the cost of the material, toxicity issue and lower photon reflectance compared to germanium $(\mathrm{Ge}),[9,13] \mathrm{GaSb}$ has become less attractive in the production of TPV cells. To date, Ge has been considered an alternative material for production of TPV cells $[12,14]$ where it is believed that efficient performance could be achieved. Ge with its low band gap $(0.66 \mathrm{eV})$ could capture long wavelength spectrum in the infrared radiation, which is matched to thermal energy. Heide et al., [15] have demonstrated single-junction Ge TPV cells with passivation layer, which results in $6.3 \%$ of energy conversion, [7, 15] which is higher than Si TPV cells with $4 \%$ efficiency [13]. It also claimed that by using stacking method such as gallium arsenide/germanium $(\mathrm{GaAs} / \mathrm{Ge})$ the performance TPV cells could be improved with energy conversion up to $16 \%$ [12]. Based on the good properties that Ge offers for PV and TPV cells, development of this attractive energy conversion device will be interesting topic to be investigated where new technology can be beneficial. However, the use of bulk Ge as substrate material in production might not be cost effective. This is because bulk Ge is an expensive and scarce material, thus making it less attractive compared toSi.

A method to overcome the high cost of bulk Ge is by using small amount of the material. For example instead of using bulk Ge wafer this can be reduced to a thinner layer, which is factor of 100 saving in material, but additional process costs will be involved. By providing Ge on insulator (GeOI) structures a good quality thin film Ge can be attained and thus, offer a low cost route. One of the GeOI approaches, namely the rapid melt growth (RMG) technique [16, 17], could potentially produce thin film Ge with quality similar to that of bulk Ge. Therefore, by applying this technique, high quality thin film Ge could be produced and hence implemented for either PV cell or TPV cell applications leading to high performance energy conversion devices at reasonably low cost. In this study, Ge photodiodes were fabricated via RMG technique and electrical characteristics were investigated. This is to demonstrate whether Ge photodiode via RMG has potential for energy conversion device. The sheet resistance of Ge photodiodes were evaluated using four-point probe method known as Kelvin measurement. This can be obtained by adopting Greek-cross test structure with aluminium (Al) pads and also a four-terminal rail test structure to the samples. The current-voltage (I-V) measurement of Ge photodiode was conducted using Wentworth prober and parameter analyser. An optical microscope and Scanning Electron Microscope (SEM, JEOL-JSM 7200) were used for sample topography inspection. 


\section{METHODOLOGY}

\subsection{Rapid Melt Growth (RMG) Process}

The rapid melt growth (RMG) process uses a micro-crucible holding the molten Ge. In the fabrication process for PVD Ge, the crucible is formed on the surface of an oxidised silicon wafer with the Ge contacting the $\mathrm{Si}$ in a seed window. The Ge is patterned into stripes and covered with a capping layer to form the micro-crucible as shown in Figure 1. Rapid thermal annealing (RTA) is applied to heat the Ge above its melting point $(938 \mathrm{oC})$ for a few seconds. After annealing, the Ge cools and crystallizes starting from the $\mathrm{Si}$ seed and continuing laterally along the crucible. The crucible can become strained due to the Ge balling phenomenon and so the capping layer was reinforced using a polycrystalline silicon (poly-Si) layer and hafnium dioxide (HfO2). This is essential to minimise Ge balling and delamination [17].

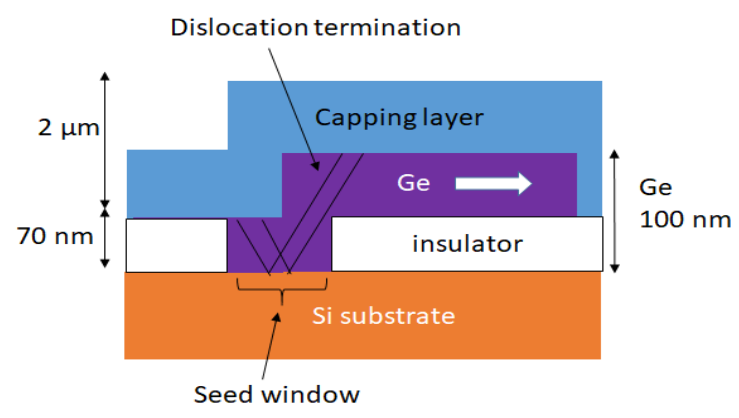

Figure 1. Dislocation termination of lattice mismatch at seed (not to scale)

\subsection{Experimeant Details}

In the early work [17], attention has been directed to producing high quality thick germanium films (100 nm and above) with the RMG technique. Results have shown that thick crystalline Ge films can be fabricated with the alteration of generic RMG materials by either using poly-Si or $\mathrm{HfO} 2$ capping layer. Film produced from these micro-crucibles have similar crystal quality to that of bulk Ge and with tensile stress [17-19]. Tensile stress has been reported to provide significant advantage for fabrication of photonic device since it can provide high hole mobilities [20,21]. In case of energy conversion device such as PV or TPV cells, a better device efficiency performance could be anticipated. Previous publications [22-24], stated that Ge films with excellent crystal quality can give better electrical performance. This evidence was supported by Collace and co-workers [25], where they found that the performance of a polycrystalline Ge photodetector deteriorated due to the poor Ge film quality. However, in commercialization of PV or solar cells, polycrystalline films have gained an interest as compared to monocrystalline due to their lower production cost. For example in the terrestrial PV applications, a polycrystalline Si device was reported [26] to give similar performance to a monocrystalline equivalent. Therefore at this stage, a Ge photodiode with polycrystalline structure will be investigated. As reported previously [27], intrinsic Ge stripe resistors have been demonstrated to have a high resistance value. By doping the Ge films either with p-type or n-type dopants, it would be expected that low resistance could be achieved. Ion implantation was selected for impurity doping of Ge due to its low temperature process. The aim of this investigation is to observe whether Ge produced along with RMG could be used in the manufacture of a photodiode by forming the $p-i-n$ device on the test samples. A diode characteristic is anticipated to be obtained from the $\mathrm{p}-\mathrm{i}-\mathrm{n}$ junction for Ge stripe arrays and square test structures. At this stage, only Ge film with partially crystalline structure was investigated.

\subsubsection{Photodiode Design And Simulation}

In this study, test structures including Greek cross; aluminium ( $\mathrm{Al}$ ) pad and rail structures were designed using LEdit software. The advantage of using a Greek cross is that the sheet resistance is extracted at the centre of the cross and an accuracy of better than $0.1 \%$ can be achieved [27-30]. The uniformity of film resistance can be determined by fabricating many small Greek cross structures on the wafer [28] and also, by having $\mathrm{Al}$ pads, probing measurement can be repeatable. In the case of single Ge stripe, a photomask with selective doping area was designed to access Ge stripe electrical properties. In this case, individual intrinsic devices will be compared to an intrinsic (un-doped) structure. A single stripe Greek cross structure was designed with $5 \mu \mathrm{m}$ width and $78 \mu \mathrm{m}$ length starting from the seed region connecting to $150 \mu \mathrm{m} \times 150 \mu \mathrm{m} \mathrm{Al}$ 
pads. Figure 2 shows the photomask design for a single stripe with intrinsic Ge. The photomasks for lateral pi-n junctions were designed with arrays of Ge stripes and with large square patterns. For Ge stripe arrays, the length of intrinsic (i) region and number of Ge stripes varied. For example each test device has a $10 \mu \mathrm{m}$ or 20 $\mu \mathrm{m}$ length intrinsic region with a set of 5 and 10 arrays stripes. By varying the number of Ge stripes and length of intrinsic region, differences in electrical characterisation are expected. To perform the electrical measurement on the Ge stripe arrays, samples were connected to rails and Al pads. Figure 3(a) shows the design of an array with $5 \mathrm{Ge}$ stripes with a $10 \mu \mathrm{m}$ length of intrinsic region. In this case, the Ge stripe is $5 \mu \mathrm{m}$ wide and $100 \mu \mathrm{m}$ long starting from the seed region. The gap between stripes is $5 \mu \mathrm{m}$ and the doped region is $30 \mu \mathrm{m}$ wide.

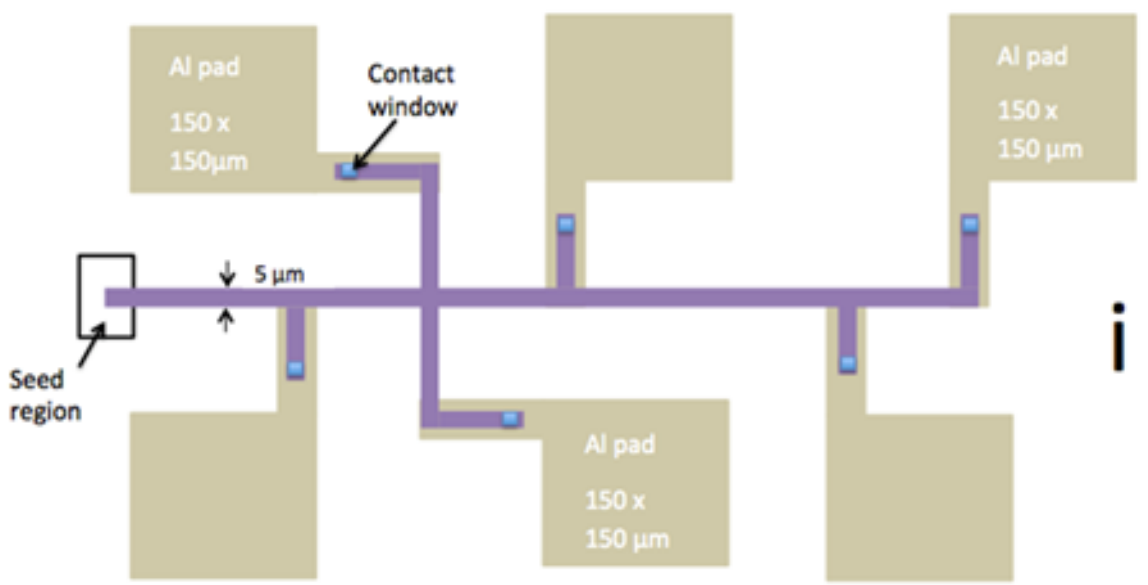

Figure 2. Photomask design of single Ge stripe with un-doped condition

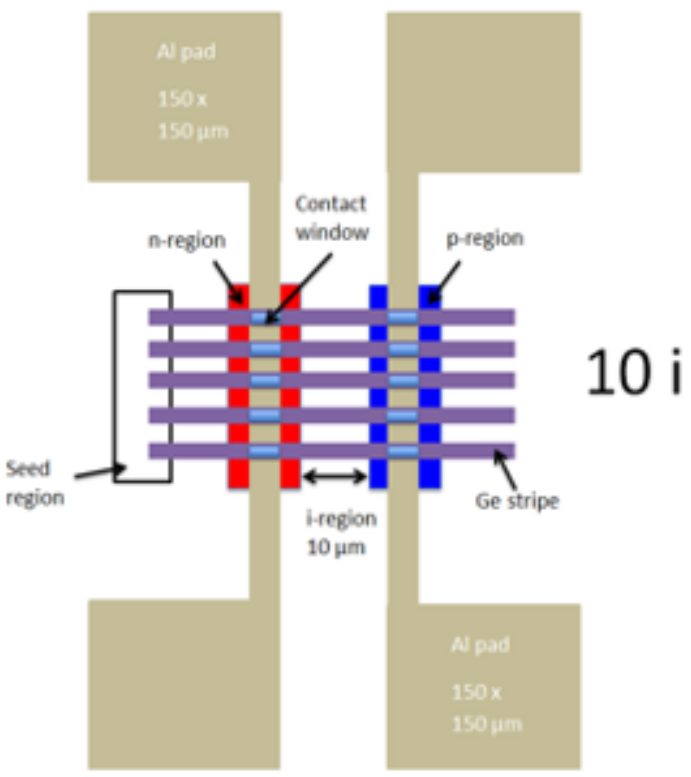

(a)

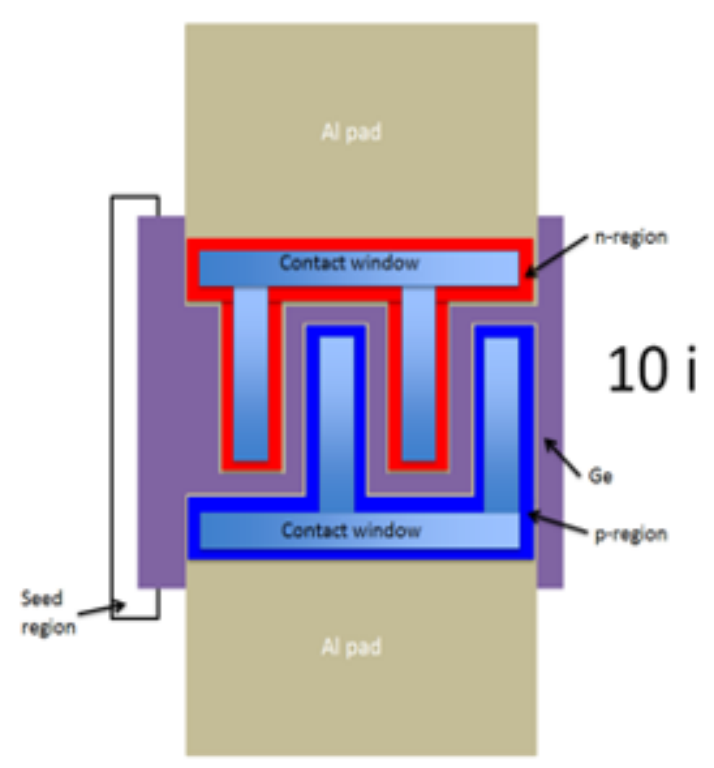

(b)

Figure 3. Photomask design of (a) arrays Ge stripes with $5 \mu \mathrm{m}$ wide and $100 \mu \mathrm{m}$ long (b) large square Ge with size $208 \mu \mathrm{m}$ x $208 \mu \mathrm{m}$

In the case of large square area, two different sizes of p-i-n junction test structures have been designed. The first square pattern is a $208 \mu \mathrm{m}$ x $208 \mu \mathrm{m}$, similar to the earlier samples. A larger $406 \mu \mathrm{m} \times$ $406 \mu \mathrm{m}$ device was also designed to see whether good quality of Ge film can be obtained. The length of intrinsic (i) region on large squares was $10 \mu \mathrm{m}$ or $20 \mu \mathrm{m}$. Figure 3(b) illlustrates a large square device design 
with p-i-n junction where the intrinsic region is $10 \mu \mathrm{m}$. According to Baine et al., [31] and Low et al., [32] a dose of $5 \times 10^{15} \mathrm{~cm}^{-2}$ of boron (p-type dopant) implanted into bulk Ge at energy of $30 \mathrm{keV}$ is enough to form a selective p-region with good performance. Dehlinger et al., [33] stated that a dose of $10^{15} \mathrm{~cm}^{2}$ of n-type dopant implanted to wafer could give diode characteristic. Based on these published results, similar amounts of dopants and energies were used to form the p-i-n Ge photodiode. Simulation software called Stopping and Range of Ions in Matter (SRIM) [34] has been used to calculate the ion profile in the Ge.

\subsubsection{Germanium Photodiode Fabrication Process}

For fabrication of Ge photodiode, multiple insulator layers namely silicon dioxide $\left(\mathrm{SiO}_{2}\right)$ and hafnium dioxide $\left(\mathrm{HfO}_{2}\right)$ were employed in the process. A $60 \mathrm{~nm}$ thick $\mathrm{SiO}_{2}$ and $20 \mathrm{~nm} \mathrm{HfO}_{2}$ were formed through thermal oxidation and atomic layer deposition (ALD), respectively. The photomask design described earlier has been used to first pattern the seed window in the insulator layer. The seed window was formed using wet etching, namely buffered HF (7:1). Ge films were sputter deposited on top of insulator layer with thickness of $170 \mathrm{~nm}$ to $500 \mathrm{~nm}$ and then patterned and etched into narrow stripes and large square shapes using reactive ion etching (RIE). A $20 \mathrm{~nm} \mathrm{SiO} 2$ layer was deposited on Ge using atmospheric pressure chemical vapour deposition (APCVD) at $450{ }^{\circ} \mathrm{C}$, to cover the whole wafer. Subsequently, prior to ion implantation, aluminium ( $\mathrm{Al}$ ) was deposited by evaporation. The selective $\mathrm{p}$ regions were patterned and etched and p-type dopant namely boron B (11)+ was introduced via ion implantation with $5 \times 10^{15} \mathrm{~cm}^{-2}$ dose at $30 \mathrm{keV}$ and tilt angle of $7^{\circ}$. After boron implantation, the Al layer was removed using wet etching. A similar process was used to form the $\mathrm{n}$ regions. The $\mathrm{n}$-type dopant, phosphorus $\mathrm{P}(31)+$ was implanted into Ge with $5 \times 10^{15} \mathrm{~cm}^{-2}$ dose at $30 \mathrm{keV}$ and tilt angle of $7^{\circ}$. Al was removed using wet etching.

Prior to dopant activation, a $1 \mu \mathrm{m}$ PECVD oxide was deposited as a passivation layer and antireflective coating. Usually, ion implantation will cause damage and lattice disorder in crystalline semiconductor material. This damage will degrade properties such as carrier mobility and affect the device performance [34]. In order to repair the damage an annealing treatment is required. The annealing will also ensure that the dopant atoms are electrically activated as they take up sites in the crystal lattice. The activation process can be performed through either furnace tube or rapid thermal annealing (RTA). At this stage, Ge films are still in amorphous state. In previous investigation [17], it was shown that the deposition of poly-Si crucible at $620^{\circ} \mathrm{C}$ changed the Ge from amorphous into a polycrystalline structure. A polycrystalline deposition step was thus used to partly crystallise the Ge and activate both type of dopants. As previously reported [32, 33] this temperature was enough to activate the dopants in Ge. Once the activation was completed, the poly-Si layer was removed using polysilicon etch. Test samples were then baked at $150{ }^{\circ} \mathrm{C}$ for one hour to dry out the $\mathrm{SiO}_{2}$, followed by contact window formation. Lastly, a metallisation layer was formed on the test samples by depositing an Al layer using evaporation. The completed Ge photodiode structure is illustrated in Figure 4.

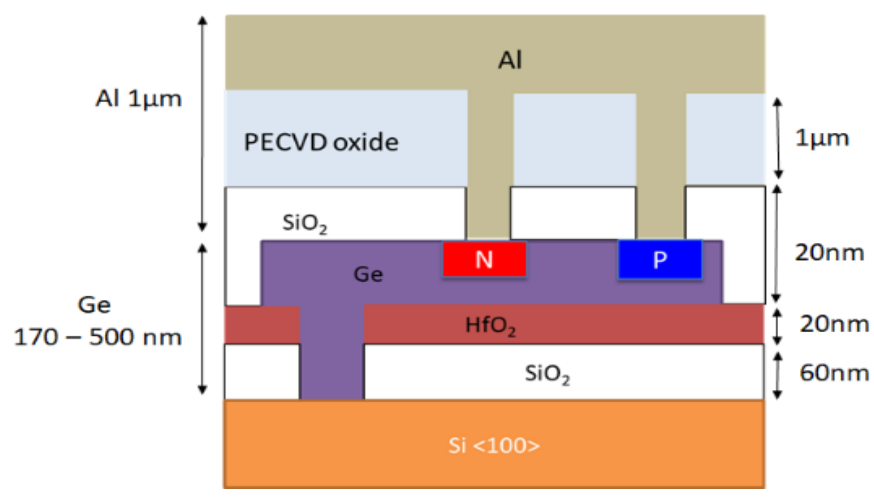

Figure 4. Ge photodiode with RMG materials (not to scale)

\section{RESULTS AND ANALYSIS}

Figure 5 shows the projected range and straggle obtained from SRIM simulation with $\sim 20 \mathrm{~nm}$ depth for phosphorus implantation. By comparison, a $\sim 41 \mathrm{~nm}$ depth is achieved with boron implantation as shown in Figure 6. Both ions implantations use $30 \mathrm{keV}$ energy, a dose of $5 \times 10^{15} \mathrm{~cm}^{-2}$ and $7^{\circ}$ tilt angle. Lower tilt angle of ion implantation was chosen to minimise the shadow effect that could introduce an additional series 
resistance in device. The simulation results have confirmed that energy and dose of ion implantations reported by researchers $[32,33]$ was sufficient for development of the Ge photodiode.

Test samples were inspected by optical microscope at each fabrication step, prior to the currentvoltage (I-V) measurement to determine if any delamination occurred. It was observed that square test structures with size $208 \mu \mathrm{m}$ x $208 \mu \mathrm{m}$ and $406 \mu \mathrm{m}$ x $406 \mu \mathrm{m}$ have delaminated after the activation process during poly-Si deposition as shown in Figure 7(a). The delamination occurred on all samples with $170 \mathrm{~nm}$ to $500 \mathrm{~nm}$ thick Ge. These results are in contrast to previous work where no cracks or delamination were observed for $212 \mu \mathrm{m} \times 246 \mu \mathrm{m}$ areas even after annealing above $938{ }^{\circ} \mathrm{C}$ as depicted in Figure 7(b). This suggests that ion implantation has changed the stress level in the Ge during poly-Si deposition at $620^{\circ} \mathrm{C}$, hence causing damage. On the other hand, good film formation on single stripe and arrays of Ge stripes was observed after poly-Si deposition and activation as shown in Figure 8(a). Figure 8(b) shows a Ge stripe array after metal deposition for samples with p-i-n structure where the intrinsic region is $20 \mu \mathrm{m}$ long. Upon good formation of test structures, I-V measurements were conducted using Wentworth prober AWP 2802 and Agilent parameter analyser on the single and arrays of Ge stripe. The electrical measurement is performed by injecting current through one pair of contacts and the voltage is measured on another contact pair. Figure 9 depicts the setup for a single stripe with four Al pads labelled as 1, 2, 3 and 4 . The fixed current is injected between pads 1 and 2; the resulting potential difference is measured between pads 3 and 4 . The measurement current is then reversed to see any differences in the voltage. The current and voltage pads are then interchanged by forcing current to pad 1 and leaving pad 4. Then the voltage drop is extracted between pad 2 and 3 and above measurement is repeated. The values of resistance are then averaged.

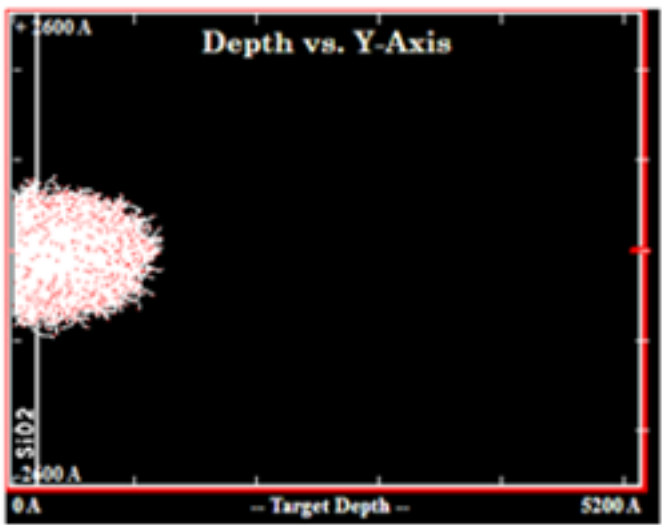

(a) Phosphorus depth

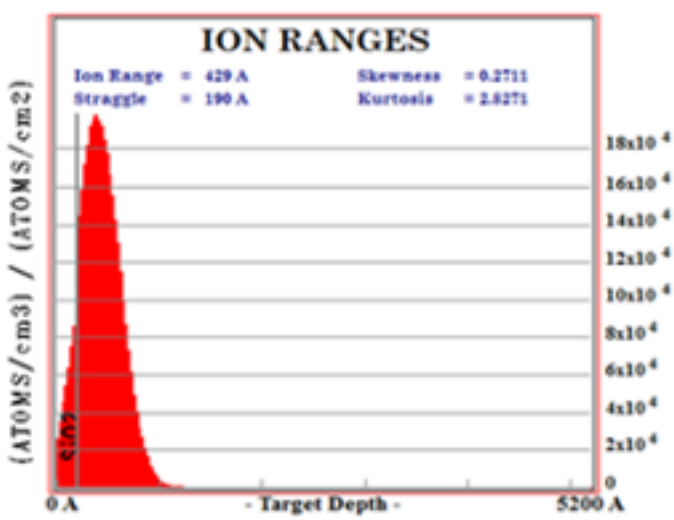

(b) Gaussian distribution

Figure 5. Simulation results for phosphorus dopant with energy of $30 \mathrm{keV}$

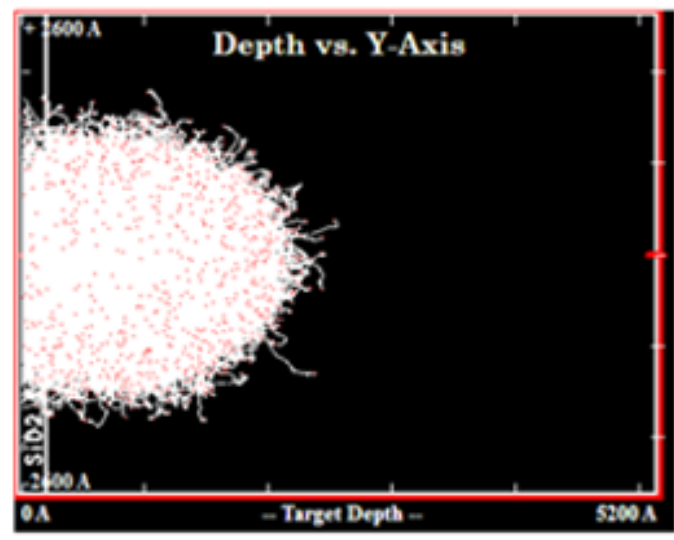

(a) Boron depth

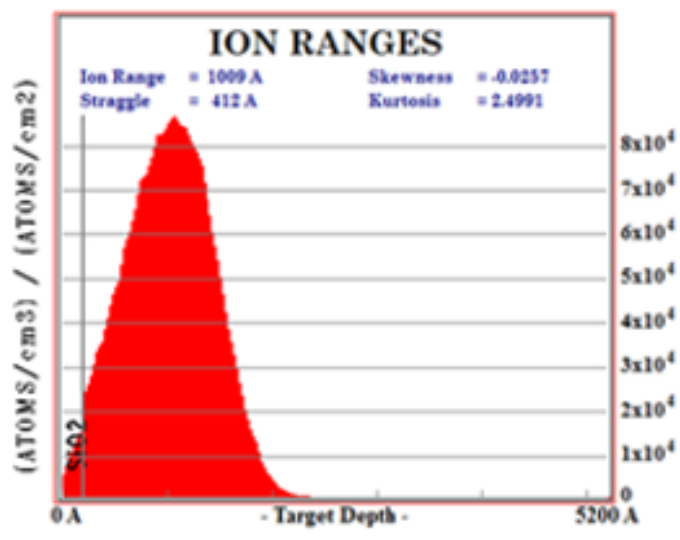

(b) Gaussian distribution

Figure 6. Simulation results for boron dopant with energy of $30 \mathrm{keV}$ 

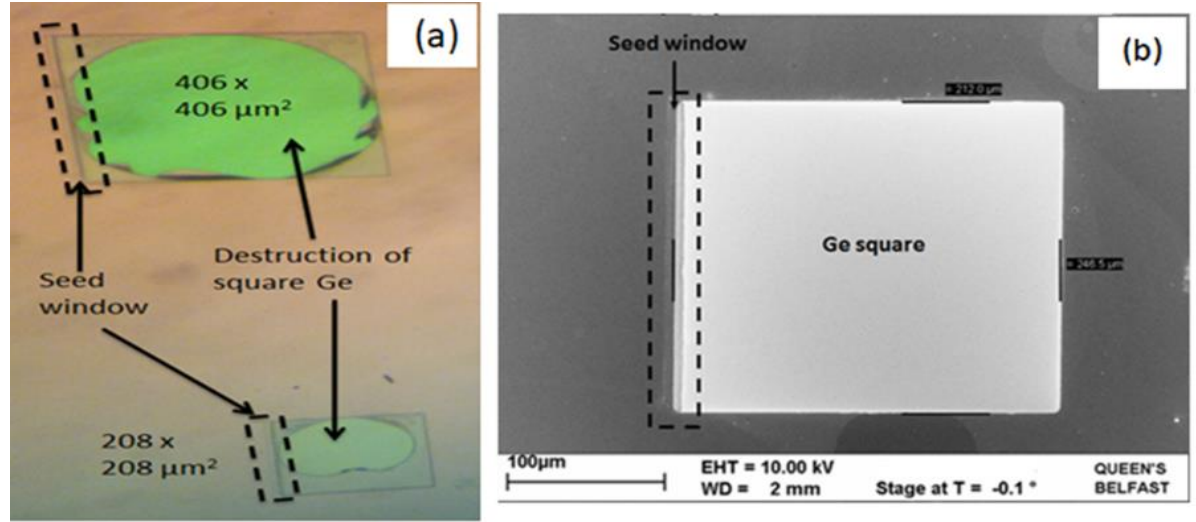

Figure 7. Photograph of (a) top view delamination squares Ge after poly-Si and activation process (b) SEM image of square Ge after RTA at $938 \mathrm{oC}$ (without ion implantation) and capping layer removal
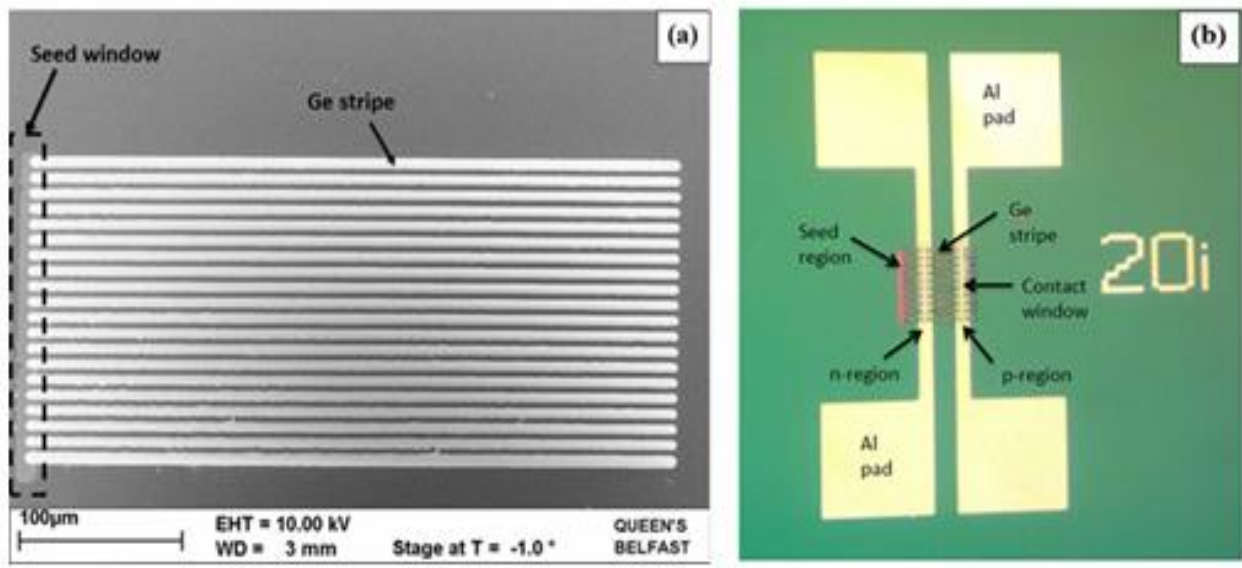

Figure 8. Photograph of (a) SEM image of arrays Ge stripes after poly-Si removal and activation process and (b) top view arrays Ge stripes after metal contact deposition

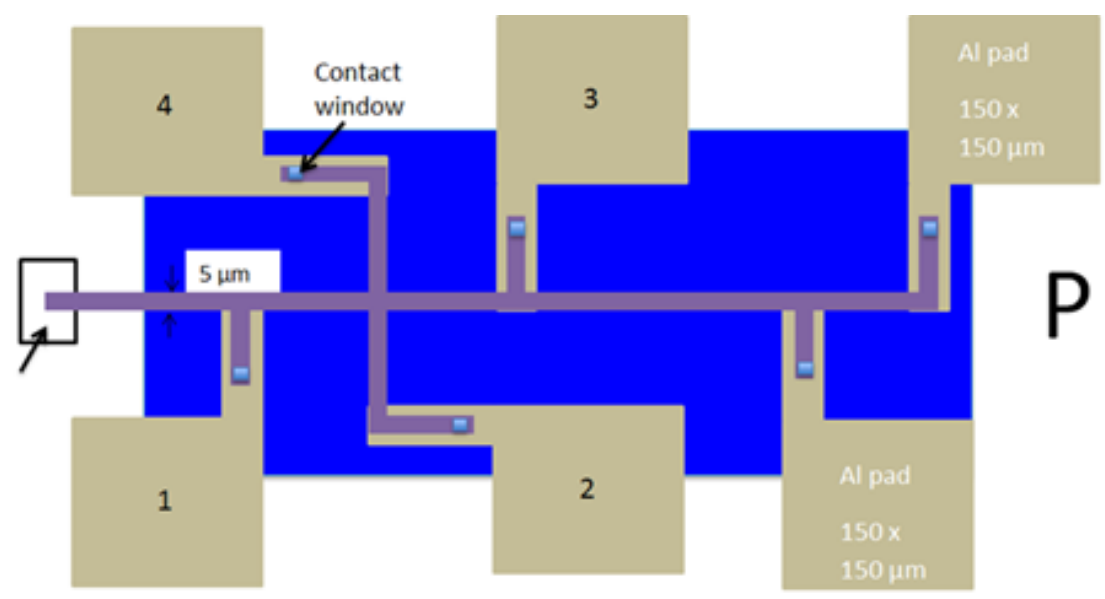

Figure 9. Illustration of electrical setting measurement

Prior to electrical measurements, a post metal anneal (PMA) was performed in the furnace at $350{ }^{\circ} \mathrm{C}$ for 30 minutes with $90 \%$ nitrogen $\left(\mathrm{N}_{2}\right)$ and $10 \%$ hydrogen $\left(\mathrm{H}_{2}\right)$. The PMA process aims to improve contact 
between Ge and metal. Following the PMA process, results show that resistor and diode characteristics could be obtained. For the single Ge stripe structure, a resistor characteristic was obtained since no junction was present. There were 3 resistor structures with different doping conditions, either intrinsic (un-doped) or extrinsic (doped). For extrinsic samples, each single Ge stripe was implanted with either p-type or n-type dopant. As expected, results on intrinsic (un-doped) single Ge stripe show that the sample gives linear resistor behavior. Most of the intrinsic samples show no difference when samples tested under illumination or in dark situation. The resistance values were calculated by taking the average slope for several devices. The overall sheet resistance, $R_{\text {sh }}$ values can be calculated using (1) [28]. The importance of sheet resistance measurement is to characterize the uniformity and conductivity of the Ge layer produced by RMG technique. The lower the sheet resistance, the better the conductivity of the materials. Thus, better electrical performance of photodiode is anticipated.

$$
R_{s h}=\frac{\pi}{\ln 2} \frac{V}{I}=4.532 \frac{\Delta V}{\Delta I} \Omega / s q
$$

Results in Table 1 show that only slight reductions of resistance values were obtained for samples doped with boron compared to intrinsic devices. For Ge doped with phosphorus, a slightly higher resistance is obtained. The reason behind small changes of resistance between intrinsic and extrinsic samples is believed to be due to the samples being only lightly doped or the dopant not fully activated. Compared to previous measurements on a $170 \mathrm{~nm}$ thick intrinsic Ge stripe resistor [27], a significant reduction of the sheet resistance can be observed as shown in Table 2. The reduction is believed to be due to the use of $500 \mathrm{~nm}$ thick Ge film as compared to $170 \mathrm{~nm}$ thick in the earlier sample.

Table 1. Summary of Sheet Resistance for Single Ge Stripe

\begin{tabular}{ccc}
\hline \multirow{2}{*}{$500 \mathrm{~nm}$ thick Ge conditions } & $\begin{array}{c}\text { Under illumination } \\
(\Omega / \mathrm{sq})\end{array}$ & Dark (No illumination) $(\Omega / \mathrm{sq})$ \\
\hline Intrinsic Ge stripe (un-doped) & 1241 & 1300 \\
Ge stripe doped with phosphorus & 1268 & 1314 \\
Ge stripe doped with boron & 1164 & 1173 \\
\hline
\end{tabular}

Table 2. Comparison of Average Sheet Resistance of Ge Stripes

\begin{tabular}{cc}
\hline Ge conditions & Dark (No illumination) $(\Omega / \mathrm{sq})$ \\
\hline $170 \mathrm{~nm}$ single Ge stripe & $0.2 \times 10^{6}$ \\
$500 \mathrm{~nm}$ single Ge stripe & $1.2 \times 10^{3}$ \\
\hline
\end{tabular}

In the case of arrays of Ge stripes with the p-i-n junction, a large population of devices showed a linear resistor characteristic regardless of Ge thickness and PMA process. Only small number of devices showed a diode characteristic and these had a high leakage current. This is believed to be due to the fact that Ge was polycrystalline in structure. The polycrystalline grain structure will impede current flow through the device and provide leakage path at the grain boundaries. Moreover, there were no significant differences observed between samples under illumination and dark conditions. Figure 10 shows results obtained from $500 \mathrm{~nm}$ thick Ge under illumination and dark situation. In this case $5 \mathrm{~mA}$ current is forced from the $\mathrm{n}$-region of the test sample. On the other hand, if the same current is being forced from the p-region of the test sample, results show it behave in the reverse direction as in Figure 11. It is noted that results obtained in Figure 11 has similar pattern to results of single Ge stripe doped with boron where samples had diode characteristic with high leakage current. It can be testified that the narrow Ge stripes produced via RMG could behave as conductive material. This is due to the samples having resistor characteristic when small amount of current (1 $\mu \mathrm{A})$ is applied either under dark or illumination situation. Results obtained from photodiode structure were unable to show saturation of current in reverse bias as expected. This is believed to be due to polycrystalline structure of the $\mathrm{Ge}$ film. An investigation for leakage to substrate was also carried out similar to I-V measurement of resistor. Electrical tests revealed a leakage current flow to substrate since the contact windows are larger than the Ge stripes. Electrical measurements have been compromised due to this leakage to the substrate. As a result electrical measurement of $\mathrm{Ge}$ photodiode via RMG could not be investigated fully. 


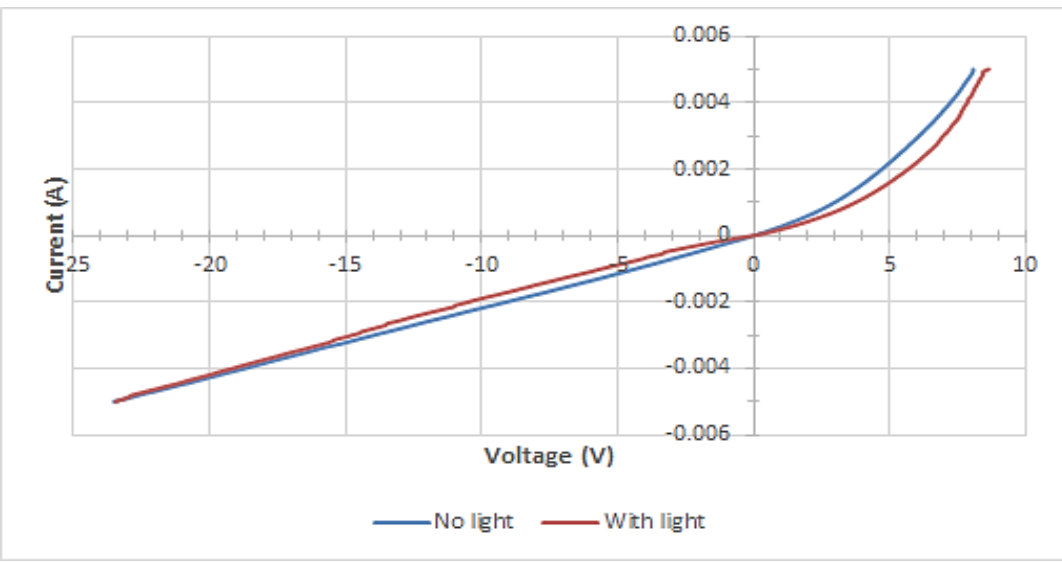

Figure 10. Results of I-V measurement of array Ge stripes with $500 \mathrm{~nm}$ thick with current forced to n-region

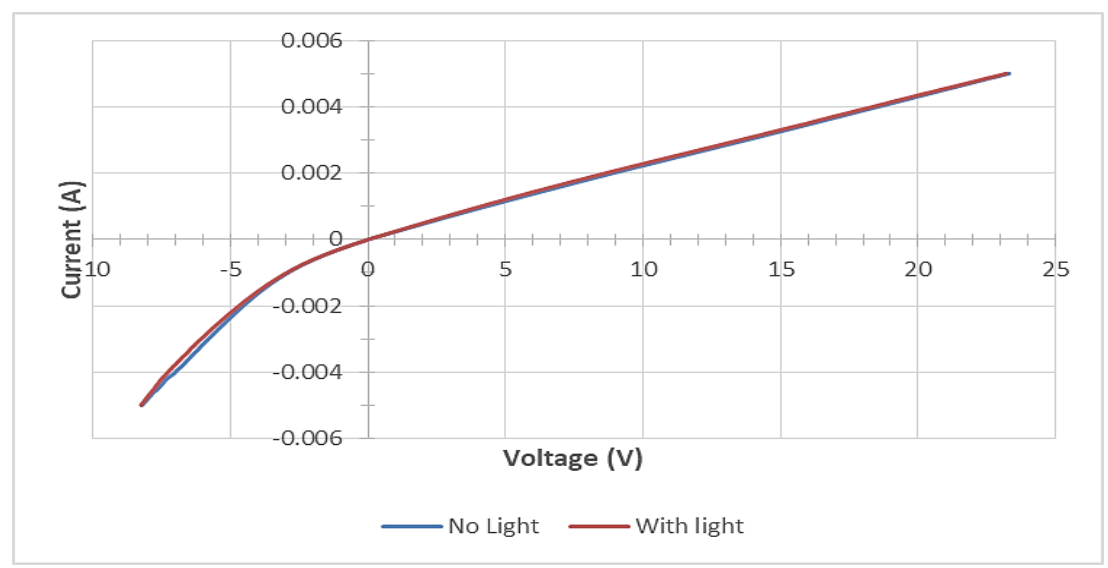

Figure 11. Results of I-V measurement of array Ge stripes with $500 \mathrm{~nm}$ thick with current forced to p-region

\section{CONCLUSIONS}

In conclusion, Ge photodiode has been demonstrated along with RMG materials. Results show that Ge square patterns with size of $208 \mu \mathrm{m} \times 208 \mu \mathrm{m}$ were unable to be obtained if implantation process was carried out to form the photodiode. Delamination was observed on all Ge films from $170 \mathrm{~nm}$ to $500 \mathrm{~nm}$ thick during the poly-Si deposition at $620^{\circ} \mathrm{C}$. This result is in contrast to previous work, where good formation of squares $(212 \mu \mathrm{m} \times 246 \mu \mathrm{m})$ had been successfully attained even after annealing at high temperature above $938^{\circ} \mathrm{C}$. This indicates that the impurity doping process has affected $\mathrm{Ge}$, hence causing delamination even at low temperature. Therefore, Ge with narrow stripe pattern is recommended to be used if the implantation process is involved in fabricating a device. The thick Ge stripe resistance has shown significant decrease compared to thin Ge resistor and as-deposited Ge samples. In the case of Ge stripe arrays with p-i-n junction, results show that a large fraction of test samples give linear I-V characteristics. A small fraction of devices give diode characteristics but with high leakage current. Only slight changes in the I-V characteristic can be observed on the single Ge stripe resistors when samples were tested under illumination and dark conditions. Ge p-i-n samples were found to have a high leakage current to the substrate which compromised device performance. As a result, the I-V characteristics of the photodiodes produced via RMG materials could not be investigated fully, and energy conversion measurement could not be established. It is recommended changes are made to the process sequence and to the contact window design and its etching process to avoid this issue. Also, it is suggested to change the activation annealing time for Ge to make it in crystalline structure instead of polycrystalline in order to minimise the leakage current. 


\section{ACKNOWLEDGEMENTS}

This work was under the financial support Tier 1 grant (Vot H216) of Universiti Tun Hussein Onn Malaysia and in collaboration with Queen's University Belfast, Northern Ireland, United Kingdom. The authors wish to thank Dr T. S. Perova, Trinity College Dublin for valuable input on the Raman analysis.

\section{REFERENCES}

[1] R. R. King, A. Boca, W. Hong, X. Liu, D. Bhusari, D. Larrabee, K. M. Edmondson, D. C. Law, C. M. Fetzer, S. Mesropian, and N. H. Karam, "Presented at the 24th European Photovoltaic Solar Energy Conference and Exhibition, Hamburg, Germany, 21-25 Sep. 2009," pp. 21-25, 2009.

[2] N. E. Posthuma, J. van der Heide, G. Flamand, and J. Poortmans, "Emitter Formation and Contact Realization by Diffusion for Germanium Photovoltaic Devices," IEEE Trans. Electron Devices, vol. 54, no. 5, pp. 1210-1215, May 2007.

[3] R. R. King, C. M. Fetrer, P. C. Colter, K. M. Edmondson, H. E. James, H. L. Cotal, H. Yoon, A. P. Stavrides, G. Kinsey, D. D. Krut, and N. H. Karam, "High-Efficiency Space and Terrestrial Multijunction Solar Cells Through Bandgap Control in Cell Structures," pp. 776-781, 2002.

[4] V. Avrutin, N. Izyumskaya, and H. Morkoç, "Semiconductor solar cells: Recent progress in terrestrial applications," Superlattices Microstruct., vol. 49, no. 4, pp. 337-364, Apr. 2011.

[5] C. Wadia, A. P. Alivisatos, and D. M. kammen, "Materials Availability Expands the Opportunity for Large-Scale Photovoltaics Deployment," Environ. Sci. Technol., vol. 43, no. 6, pp. 2072-2077, 2009.

[6] K. Buker, N. Alonso-Vante and H. Tributsch, "Photovoltaic output limitation of n-FeS 2 (pyrite) Schottky barriers: A temperature-dependent characterisation," J. App. Phys. vol. 72 (12), pp. 5721-5728, 1992.

[7] H. Mousazadeh, A. Keyhani, A. Javadi, H. Mobli, K. Abrinia, and A. Sharifi, "A review of principle and suntracking methods for maximizing solar systems output," Renew. Sustain. Energy Rev., vol. 13, no. 8, pp. 1800-1818, Oct. 2009.

[8] S. S. Sun, N. S. Sariciftci, "Organic Photovoltaics Mechanism, Materials and Devices”, Taylor \& Francis, 2005.

[9] K. Qiu and a. C. S. Hayden, "Development of a silicon concentrator solar cell based TPV power system," Energy Convers. Manag., vol. 47, no. 4, pp. 365-376, Mar. 2006.

[10] V. M. Andreev, V. a. Grilikhes, V. P. Khvostikov, O. a. Khvostikova, V. D. Rumyantsev, N. a. Sadchikov, and M. Z. Shvarts, "Concentrator PV modules and solar cells for TPV systems," Sol. Energy Mater. Sol. Cells, vol. 84, no. $1-4$, pp. 3-17, Oct. 2004.

[11] G. Taraschi, A. J. Pitera, and E. a. Fitzgerald, "Strained Si, SiGe, and Ge on-insulator: review of wafer bonding fabrication techniques," Solid. State. Electron., vol. 48, no. 8, pp. 1297-1305, Aug. 2004.

[12] V. P. Khvostikoz, P. Y. Gazaryan, S. V Sorokina, N. S. Potapovich, A. V Malevskaya, N. A. Kaluzhniy, M. Z. Shvarts, and V. M. Andreev, "Photovoltaic Cells Based on GaSb and Ge for Solar and Thermophotovoltaic Applications," J. Sol. Energy Eng., vol. 129, no. August, pp. 291-297, 2007.

[13] B. Bitnar, W. Durisch, and R. Holzner, "Thermophotovoltaics on the move to applications," Appl. Energy, vol. 105, pp. 430-438, May 2013.

[14] E. U. Onyegam, D. Sarkar, M. Hilali, S. Saha, R. a. Rao, L. Mathew, D. Jawarani, J. Mantey, M. Ainom, R. Garcia, W. James, and S. K. Banerjee, "Exfoliated, thin, flexible germanium heterojunction solar cell with record $\mathrm{FF}=58.1 \%$,"Sol. Energy Mater. Sol. Cells, vol. 111, pp. 206-211, Apr. 2013.

[15] J. van der Heide, N. E. Posthuma, G. Flamand, W. Geens, and J. Poortmans, "Cost-efficient thermophotovoltaic cells based on germanium substrates," Sol. Energy Mater. Sol. Cells, vol. 93, no. 10, pp. 1810-1816, Oct. 2009.

[16] Y. Liu, M. D. Deal, and J. D. Plummer, "High-quality single-crystal Ge on insulator by liquid-phase epitaxy on Si substrates," Appl. Phys. Lett., vol. 84, no. 14, pp. 2563, 2004.

[17] N. Zainal, S. Mitchell, D. McNeill, M. F. Bain, B. M. Armstrong, P. Baine, D. Adley, and T. S. Perova, "Characterization of Rapid Melt Growth (RMG) Process for High Quality Thin Film Germanium on Insulator," ECS Trans., vol. 45, no. 4, pp. 169-180, 2012.

[18] Litvin, D. Adley, T. S. Perova, N. Zainal, S. J. N. Mitchell, D. W. McNeill, M. F. Bain, B. M. Armstrong, and P. T. Baine, "Proceedings of the Microscopy Society of Ireland," in MSI 2011, no. August, p. 61, 2011.

[19] T. S. Perova, N. Zainal, D. Adley, S. J. N. Mitchell, D. W. Mcneill, M. F. Bain, B. M. Armstrong, and P. Baine, "Investigation of crystalline quality and stress in germanium stripes fabricated by rapid melt growth process," Silicon 2012, 2012.

[20] G. Chang, S. Chang, and S. L. Chuang, "Theory for n-type doped, tensile-strained Ge-Six Gey Sn 1-x-y quantum-well lasers at telecom wavelength," vol. 17, no. 14, pp. 11246-11258, 2009.

[21] M. L. Lee, E. a. Fitzgerald, M. T. Bulsara, M. T. Currie, and A. Lochtefeld, "Strained Si, SiGe, and Ge channels for high-mobility metal-oxide-semiconductor field-effect transistors," J. Appl. Phys., vol. 97, no. 1, p. 011101, 2005.

[22] L. Vivien, D. Marris-Morini, J.-M. Fédéli, M. Rouvière, J.-F. Damlencourt, L. El Melhaoui, X. Le Roux, P. Crozat, J. Mangeney, E. Cassan, and S. Laval, "Metal-semiconductor-metal Ge photodetectors integrated in silicon waveguides," Appl. Phys. Lett., vol. 92, no. 15, p. 151114, 2008.

[23] L. Chen, P. Dong, and M. Lipson, "High performance germanium photodetectors integrated on submicron silicon waveguides by low temperature wafer bonding," Opt. Express, vol. 16, no. 15, pp. 11513-8, Jul. 2008.

[24] F. Gity, A. Daly, B. Snyder, F. H. Peters, J. Hayes, C. Colinge, A. P. Morrison, and B. Corbett, "Ge/Si heterojunction photodiodes fabricated by low temperature wafer bonding," Opt. Express, vol. 21, no. 14, p. 17309, Jul. 2013. 
[25] L. Colace, G. M. a. Altieri, and G. Assanto, "Waveguide photodetectors for the near-infrared in polycrystalline Germanium on silicon," IEEE Photonics Technol. Lett., vol. 18, no. 9, pp. 1094-1096, May 2006.

[26] J. Martin, "Monocrystalline vs Polycrystalline Solar Panels: Busting Myths," Solar Panels/Modules, Solar System Products, 2012. [Online]. Available: http://www.solarchoice.net.au/blog/monocrystalline-vs-polycrystalline-solarpanels-busting-myths/. [Accessed: 17-Jan-2014].

[27] N. Zainal, S.J.N. Mitchell, D. W. McNeill "Electrical Characterisation of PVD Germanium resistors with Rapid Melt Growth (RMG) process,” AIP Conf. Proc. 2030, 020109-1 pp.020109-7; 2018.

[28] D. K. Schroder, "Semiconductor Material and Device Characterization" 3rd. Edit., A John Wiley and Sons, Inc., Publication, Tempe, Arizona, 2006.

[29] S. Enderling, C. L. Brown, S. Smith, M. H. Dicks, J. T. M. Stevenson, M. Mitkova, M. N. Kozicki, A. J. Walton, and N. Si, IEEE Trans. Semicond. Manuf. 19, pp. 2-9, 2006.

[30] W. Groenland, R. A. M. Wolters, A. Y. Kovalgin and J. Schmitz, "Four point probe structure with buried electrodes for the electrical characterization of ultrathin conducting film" IEEE International Conference Microelectronic Test Structure, pp. 191-195, 2009.

[31] P. T. Baine, H. S. Gamble, B. M. Armstrong, S. J. N. Mitchell, D. W. McNeill, P. V Rainey, Y. H. Low, Y. W. Low, and D. Tantraviwat, "Germanium MOS transistors on sapphire and alumina platforms," 2009 IEEE Int. SOI Conf., pp. 1-2, Oct. 2009.

[32] Y. W. Low, D. Tantraviwat, P. V Rainey, P. T. Baine, D. W. Mcneill, S. J. N. Mitchell, B. M. Armstrong, and H. S. Gamble, "Low temperature processes for manufacture of germanium MOS transistor," EuroSOI 2009., pp. 143-144, 2009.

[33] G. Dehlinger, S. J. Koester, J. D. Schaub, J. O. Chu, Q. C. Ouyang, and A. Grill, "High-speed germanium-on-SOI lateral PIN photodiodes," Photonics, vol. 16, no. 11, pp. 2547-2549, 2004.

[34] J. F. Ziegler, M. D. Ziegler, and J. P. Biersack, "SRIM-The stopping and range of ions in matter (2010)," Nucl. Instruments Methods Phys. Res. Sect. B Beam Interact, with Mater. Atoms, vol. 268, no. 11-12, pp. 1818-1823, Jun. 2010.

\section{BIOGRAPHIES OF AUTHORS}

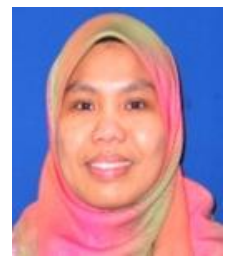

Nurfarina Zainal is a lecturer at Faculty of Electrical and Electronic Engineering, University Tun Hussein Onn Malaysia, Malaysia. She obtained M.Eng in Electrical and Electronic Engineering in 2008, from Swansea University, United Kingdom. In 2014, she received her Ph.D. in Electrical and Electronics Engineering from Queen's University Belfast, United Kingdom. Her current research interests are in novel semiconductor materials and devices, graphene and others organic materials for sensor structures and biomedical applications.

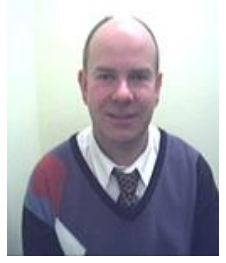

S. J. Neil Mitchell is senior lecturer at Queen's University of Belfast, United Kingdom. He has published over 170 papers including journals and conference proceedings He has over 30 years' experience in microelectronics and microelectromechanical systems technology. His current research interests are primarily in technology for fabrication of microsystems and microsensors. He led the UK element of an international project on micromachined photoacoustic sensors for greenhouse gas detection in collaboration with partners in USA, Ireland and Finland. Other research projects have included collaborations with the European Space Agency on atmospheric sensors; with UK industry on high sensitivity nanowire piezoresistors for pressure sensor applications and sensor structures for biomedical applications.

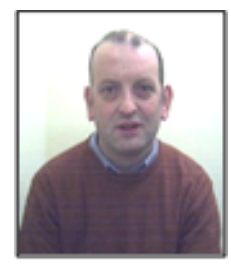

David. W. McNeill is a senior lecturer at Queen's University of Belfast, United Kingdom. He has published over 120 papers including journals and conference proceedings. His current research interests are novel semiconductor materials and devices, including germanium and twodimensional semiconductors, and MEMS materials and devices. He has partnered with researchers in the USA and the Republic of Ireland on two recent collaborative projects on semiconductor interfaces and two-dimensional semiconductors respectively. He is currently working on FET-based biomedical sensing technologies in collaboration with Dr Mitchell.

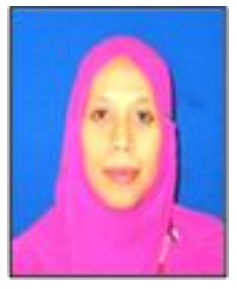

Warsuzarina Mat Jubadi is a senior lecturer at Faculty of Electrical and Electronic Engineering, University Tun Hussein Onn Malaysia, Malaysia. She obtained B.Eng in Electrical and Electronic Engineering and M.Eng in Electronic Telecommunications in 2001 and 2006, respectively, from University Teknologi Malaysia, Malaysia. In 2015, she received her Ph.D. in Electrical and Electronics Engineering from The University of Manchester, United Kingdom. Her current research interests includes analog and digital system design, device modelling and simulation of high RF and low power devices based on silicon and compound semiconductor materials. 